\title{
Teachers' Perception on the Challenges of Continuous Assessment Implementation between 2017 and 2018 in Zimbabwean Primary and Secondary Schools
}

\author{
Silas Sithole, Dairai Darlington Dziwa, PhD, and Melody Matsvange \\ Great Zimbabwe University \\ *Corresponding Mail: ssithole@gzu.ac.zw
}

\begin{abstract}
Continuous assessment is an integral part of the instruction as it determines whether the goals of education are being met during or at the end of the instructional period. The updated curriculum (2015-2022) in the Zimbabwean Primary and Secondary Schools introduced the continuous assessment which was abandoned a few months after its inception. This study sought to evaluate from the teachers' perspective the challenges which led to premature abandoning of the continuous assessment aspect. Qualitative approach was employed and the case study design. Questionnaires and focus group discussions were used as the data generation tools. A total of 55 in-service teacher education students at a University in Zimbabwe were conveniently sampled to participate in the study since they were the information rich cases. The study revealed that teachers were not prepared to implement the continuous assessment for various reasons. There was poor planning, preparation and implementation of the curriculum innovation. In the light of these findings, the study recommends that staff development programs for teachers as well as adequate consultations should be done before implementing new curriculum innovations.
\end{abstract}

Keywords: Continuous Assessment, curriculum innovation, implementation barriers, updated curriculum

\section{Introduction}

Continuous assessment is an effective strategy used in teaching and learning at both primary and secondary schools to evaluate the instruction process. In 2017 and 2018, the Zimbabwe Ministry of Primary and Secondary Education (MoPSE) mandated schools to administer a national continuous assessment model but its innovation was abandoned few months after starting. Though teachers used to administer their own tests and quizzes as forms of continuous assessment, the marks never contributed to the final national grades of the learners (Curriculum Framework for Primary and Secondary Education, 2015-2022). Teachers, among other stakeholders such as learners, parents, community and academia, showed discomfort with the implementation hence the assessment strategy was rejected. The objective of this study was to evaluate the challenges in implementing continuous assessment particularly from the perception of teachers as implementers which led to the abortion of the program. Hence the findings can be a basis to generate facts which policy makers may adopt in future plans to implement continuous assessment again.

The Ministry of Primary and Secondary Education in Zimbabwe introduced a lot of reforms which included change in content as well as bunching and debunching of subjects including the assessment formats. A new curriculum which was partly based on Nziramasanga's report (1999), introduced an 'outcome-based curriculum. The outcome basedcurriculum is broad-based curriculum which links employment related skills with school content in sync with the new global trajectory (Dube \& Jita, 2018). In terms of assessment methods, the old curriculum which was inherited from the Rhodesia government was criticized for depending much on summative evaluation as its mode for assessment. Such terminal assessment procedures could be affected by unforeseen disturbances and events on that particular day which would not reflect the learners' capabilities of the whole learning period. 
Therefore, new curriculum advocated for a continuous assessment which could also capture the performance of learners throughout the learning period.

The introduction of the updated curriculum meant that formative/continuous and summative assessments were to be fused together to come up with a robust assessment system in the education sector in Zimbabwe (Curriculum Frame work for Ministry of Primary and Secondary Education, 2015 to 2022). The Herald (7 July 2017) newspaper documents that ... "the introduction of continuous assessment (CA) in the new curriculum was crucial to the teaching and learning process because this form of assessment would provide useful information ..... thus giving evidence about how candidates are consuming the curriculum" (p.1).

The effort by the government to introduce continuous assessment in schools faced some challenges to be expounded in this paper and had to be unceremoniously abandoned. Ugwu (2005) in Ali and Ajibola (2015) observed that the relevance of any curriculum is determined only when it has been implemented. Cooper, (2017) in his wisdom also observed that for a new curriculum to be fully accepted, not for it to be a mere paper exercise in the teaching and learning practices, it should appreciate and overcome some of the barriers to curriculum implementation. Thus CA could not smoothly take off of the ground because of the terrain it went through which had some bumps and humps along the way (Dube and Jita, 2018).

Researches were made on the implementation of the Zimbabwe's 2015-2022 Competence Based Curriculum in 2018, for example Curriculum review process in the context of ZIMASSET (Nziramasanga, 2018), Zimbabwe's teacher concerns regarding the implementation of the new curriculum, (Zindi, 2018), Celebrating the MoPSE Curriculum Frame work for Zimbabwe, (Makuvaza, 2018), Possibilities of enhancing efficacy in the current curriculum Review exercise through curriculum analysis (Maravanyika, 2018) and Rethinking Technical and Vocational Education and training in the context of the Curriculum Framework for primary and secondary education 2015-2022, (Nherera, 2018) but none has looked into the implementation challenges that faced the process, resulting in it being prematurely aborted. It is against this background that the researchers explored the implementation challenges under the auspices of the updated curriculum and tried to relate this experience to the academic literature in Zimbabwe and elsewhere, with a view to contextualize findings and allow recommendations for a broader applicability of the findings. At one time, the Ministry of Primary and Secondary Education was dragged to court (Nkala, 2017) by stakeholders who were totally against the implementation of this updated curriculum in the country and as a result, it was abandoned.

Inclusion of the CA was introduced in Zimbabwean schools in 2017 but it was aborted a few months after its inception. Continuous assessment has many advantages in evaluating performance of learners but its implementation in Zimbabwe hit a mysterious snag. This study was conducted at a time when the government of Zimbabwe was still contemplating reintroducing this worthwhile assessment program (The Sunday News, 3 June 2018). The study therefore sought to establish from teachers' perspective, challenges that hindered the implementation of the CA aspect of the curriculum in Zimbabwean Primary and Secondary Schools. The main research question which guided this study was: what are the teachers' perceptions about the aborted continuous assessment practice in Zimbabwe? The study was further guided by the following specific research questions:

1. To what extent were teachers prepared to implement the CA in Zimbabwe?

2. What were the views of the teachers on reasons to the failure of the CA implementation?

3. What were the teachers' views with regard to limited resources in the process of implementing the CA program?

\section{Theoretical Framework}

Continuous assessment is the evaluation of a learner over a period of time, assessing a variety of attitudes and skills which is more effective than the ordinary tests (Ferreira \& Schulze, 2014). Thus continuous assessment is a robust and worthwhile tool which enhances a fair and accurate method of learner assessment in schools when compared to the terminal examinations.

Students need to construct the meaning of knowledge from learning experiences. Constructivism emphasizes on student-centered learning and students actually can learn more by actively generating knowledge by themselves. Guided by this theory, the study is hinged on the premise of constructivism as learners were given tasks and projects to produce knowledge during 
their learning. In elaborating the constructivism theory, Elliot, et al (2000) states that students actively construct knowledge and reality is determined by the experiences of the learners. Constructionism believes in personal construction of knowledge and is affected by the interaction of new and previous events. In continuous assessment, students learn through constructing meaning by use of nationally assessed tasks implemented by the schools forming the CA.

The Framework for MoPSE in Zimbabwe for the period 2015 to 2022 posits that "assessment is...concerned with measuring learners' performance against the set standards or benchmarks as defined by the [same] curriculum". Thus that this is an on-going process which ranges from what happens to teachers and learners to test writing that measures the success of a training program. The Herald, 7 July 2017 defined CA as the assessment of learner development throughout the entire period of study, rather than solely by the examination at the termination of the course. CA is a strategy that can be used by classroom teachers to implement and establish knowledge gain, attitude and skills acquired through learning in the school environment (Agonafer \& Tadese, 2015). Some authors indicate that CA positively affects the affective, cognitive or behavioral outcomes as well as student perceptions of their learning, engagement and behavior (Chaurura, 2017). Kidane (2013) opines that CA is reliable in enlightening the real changes in the learners' behavior. It is an inclusive and powerful means of assessing learners' progress as well as improving instruction. That is, it shows whether the teaching was done effectively on particular skills or topics and teachers then make up for the areas that need attention and this improves instruction.

\section{Research Methodology}

This study adopted a qualitative case study approach. One of the advantages of the case study design is that it enables the researchers to gain an understanding of the participants' views in their natural environment or setting (Ridder, 2017).

\section{Population and Sampling}

A population according to Creswell and Creswell (2018) includes members where the investigator gains information and draws conclusions from. The population to this study consisted of school teachers in Zimbabwe. Fifty-five (55) student teachers studying towards a Bachelor of Education (In-service degree program) at the Great Zimbabwe University were conveniently selected to participate in the study. The sample consisted of 22 teachers from the Primary and 33 from Secondary Schools from around Zimbabwe who were studying at Great Zimbabwe University at the time of the study. These were found suitable because they were classroom teachers during the period when CA was shortly introduced in schools nationwide.

\section{Instrumentation and Data Collection}

Questionnaires and focus group discussion guides were used to generate data on the participants' perceptions towards the implementation challenges of the CA in schools in Zimbabwe. The questionnaire had open-ended items to allow participants' free expression of their opinions. A focus group discussion, according to Sanders, et al. (2012), is for clearly defined interface discussion of participants. Four focus group discussion sessions, each with twelve (12) participants, were conducted in this study. Thus, three researchers administered the focus group discussion to a total of 48 participants while the other one facilitated the discussion with the other 7 participants. The focus group discussions lasted for about one and quarter hours for each session.

\section{Ethical Considerations}

Participants were not coerced to take part in the study, hence it was voluntary and they were free to withdraw at any time they felt to do so. To protect the identity of participants, pseudonyms were used in the study and this was made known to participants. Information gathered was also treated in utmost confidence so that participants would not be harmed in any way.

\section{Validity and Reliability}

The instruments were subjected to two experts for review against the research questions to ensure acceptable validity. Triangulation was adopted for reliability. The use of two different tools (questionnaires and focus group discussion) further ensured the reliability of the data.

\section{Results}

The study explored the perception of teachers on the challenges of implementing the CA in the context of the Zimbabwe updated curriculum from 2015 to 2022. Responses from the semi-structured interviews and the focus group discussions were read several times and data was categorized into themes developed from research questions. Four categories emerged from the themes and were

138 East African Journal of Education and Social Sciences (EAJESS) 2(2)136-143 
presented narratively through the research questions that guided the study.

Research Question 1: To what extent were teachers prepared to implement the CA in Zimbabwe?

Participants indicated that teachers were not prepared to administer the Continuous Assessment process in schools in Zimbabwe. This was indicated by the following excerpts, extracted from the focus group discussions:

Teachers were not prepared to implement this program because most of them were not competent to supervise the tasks. Teachers needed to be re-trained on how to administer these tasks and in many cases teachers' manuals took long to reach schools thereby exposing teachers' failure to deliver, umm it was embarrassing for some teachers to inform their classes that they didn't have answers as to how the tasks should be done (Mr Moyo-Focus Group).

Another respondent had this to comment on the implementation challenges:

Teachers were not prepared to supervise the Continuous Assessment tasks because they felt that it was something that was forced down to them by the Ministry [Primary and Secondary Education] without proper consultations. Facilitators of workshops had no answers to some of the questions raised by the participants and this created pandemonium among teachers (Mrs Mubayiwa-Focus Group).

The questionnaire responses indicated that the majority of the participants were of the same view that teachers were not prepared to supervise the Continuous Assessment in schools. The following were excerpts from participants: "Teachers wanted to be retrained to supervise these assessment tasks and they were too many hence labor intensive" (Teacher John-Focus Group).

CA brought about a lot of challenges because the tasks/projects from ZIMSEC were too many, hence it was difficulty for teachers to run the school because learners will be moving up and down the whole day under the guise of researching. That led to time tabling challenges as well, the number of teachers in schools was supposed to increase but the Ministry couldn't do that. This strained and demoralised teachers (Mr gumbo-Questionnaire).
The responses above point to the fact that teachers were not ready to supervise the Continuous Assessment in schools. Given this scenario, they would do anything within their power to make sure that the program fails.

The majority of participants indicated that tasks were too many both for the Primary and the Secondary schools. The focus group discussion had the following comments from participants:

The tasks were too many for the learners and teachers. Learners at secondary level were taking at least eleven learning areas or subjects and each learning area had a task or project. This extra load came down heavy to the lowly paid Zimbabwean teacher and coupled with shortage of resources, among other challenges. (Miss Pakumupasa-Focus Group).

Another participant had this to comment on the implementation challenges: "It was difficult to cover the syllabus; most of the learners would leave their classrooms to solicit information for projects that affected the smooth flow of lesson delivery. Umm continuous assessment was just bad" (Mr Mafuriranwa-Focus Group).

On the questionnaire responses, many participants were of the view that the task was too many for the already burdened teacher.

Tasks were too many for learners and teachers because of the high teacher-pupil ratios in some schools. A teacher taking a class of fifty-five learners would have to supervise all these learners. Added on to that, students had no background knowledge on these tasks, so they tended to copy from friends, hence defeating the purpose of the exercise (Miss ShokoQuestionnaire).

Furthermore, it was established that:

The number of tasks was unbelievably high, making it difficult for teachers and pupils to cope. The tasks were introduced and no reduction was done on the number of subjects done by pupils and this created a lot of problems for teaching and learning in schools. There was chaos in schools due to these tasks. (Mr Dambuza-Questionnaire). 
Research Question 2: What were the views of the teachers on reasons to the failure of the CA implementation?

In the focus group discussion, some participants were of the view that CA shouldn't be introduced again due to the problems they encountered during the short period when the program was implemented in schools. Participants were visibly not happy to hear about the CA in schools. Researchers had to explain that this was only a study to solicit their views about the program, not that it was to be introduced again. This is what one of the respondents revealed:

First and foremost there is need for staff development programs for subject teachers on how to supervise the tasks so that teachers as implementers are confident when it comes to implementation of the program. Other stakeholders such as parents should also have their input right from the start so that they will support the learning of their children through providing resources such as stationery and other necessities (Mr Mashavakure-Focus Group).

On the same note, the other respondent had this to say:

The Ministry [Primary and Secondary Education] should do a lot of work to improve its image to the stakeholders and the nation at large. On the previous curriculum design, formulation and implementation, the politicians dictated proceedings and this was not a health state of affair. The ministry should engage stakeholders genuinely to come up with a curriculum that is people driven, not forced down to schools like what transpired on the previous exercise (Mr Dube-Focus Group).

The last respondent revealed that "Class sizes were too high for the proper supervision of these tasks and projects. More teachers could be availed to reduce teacher-student ratios to manageable levels (Miss Muzara-Focus Group).

From these findings, it can be revealed that the change should have involved school stakeholders before it was implemented. Therefore, one of the reasons as to why the change was not successful is that stakeholders' views were not considered and therefore, teachers, particularly, were not ready to support it probably because they did not own it but more so because of limited resources amid the big class sizes. The next question went further to explore what teachers under investigation said about the limited resources.

Research Question 3: What were the teachers' views with regard to limited resources in the process of implementing the CA program?

Respondents showed that the continuous assessment was marred by lack of resources.

Teachers went further exposing their feelings regarding the limited resources in the process of implementing the CA program. One of the respondents revealed that:

Resources were grossly inadequate to man the CA program in schools. In my view it was not wise for the government to introduce a program that was not supported by available resources. There was need for teacher manuals, to guide them on how to go about unpacking the new tasks. The Ministry can consult partners such as donors to provide resources for a new program like the CA. (Mr Mabena- Focus Group).

The other respondent went on saying,

The updated curriculum was not properly funded by the government; hence there was a need for text books, teacher's guides, training of teachers and all resources that go with introduction of a new curriculum. The CA was a final blow to poor schools with low enrolments such as satellite schools. Providing for the need of schools such as funding workshops as well as providing resources was a very difficult task ( $\mathrm{Mr}$ Nkomo- Questionnaire).

Finally, it was revealed that "high enrolment of pupils in some schools meant that there was need to employ more teachers to assist with the increased work load but alas no more teachers were recruited, and this strained the lowly paid and over stretched teacher" (Mrs Chisavo- Focus Group).

\section{Discussion}

The study explored teachers' perceptions on the challenges faced by MoPSE in implementing the CA in schools in Zimbabwe. Although CA is a significant indicator to learner performance in schools that guides them to make preparations for examinations and make knowledgeable selections of career choices and further studies (Der Berg \& Shepherd, 
2015), findings indicate that teachers were not prepared to administer the CA process. Teachers felt that the CA was a program that was forced down on them without proper input from stakeholders. Obinna (2007) in Ali and Ajibora (2015) shows that teachers are normally left out when decisions on education matters are made concerning their welfare. Teachers could not properly supervise the tasks probably because they needed guidance and they did not have adequate knowledge on how to supervise.

Findings also indicated that the other problems of the CA in Zimbabwe was that too many tasks were made and this hindered the smooth take off of the program because it was very difficult to successfully implement it when all the thirteen or so subjects or learning areas had a task that needed to be supervised by teachers. Literature contends that teachers' stressful workload affects curriculum implementation (OECD, 2019). Thus It was difficult for them to assist learners because of the numerous tasks learners had to undertake when the new program was introduced.

Abejehu (2016) showed that CA is an essential part of daily classroom teaching and an important tool to guarantee quality teaching and learning. Learners should therefore be guided continuously and regularly to look at their performance and achievement in the different facets of their learning instead of just giving them examinations that come at the end of the course and does not assess the whole academic chain (Bedada, 2012). Against this observation, it was not easy for the teachers to evaluate the teaching exercise if they had no knowledge about the program.

The introduction of the new curriculum in Zimbabwe was deterred by shortage of resources, both human and material. This was consistent with literature as Kapambwe (2010) had similar observation when he found that many teachers complained about shortage of resources when CA was introduced in Zambia. Another finding also showed that class sizes needed to be reduced to manageable levels (Berhe \& Embiza, 2015) through recruitment of more teachers when introducing new innovations. Results showed that poor schools were the worst affected by the shortage of resources because they could not afford to fund teachers for attending workshops. Neither did they acquire stationery for the CA program thereby putting them at great disadvantage. Therefore, there was a general unpreparedness by teachers to implement the new curriculum in schools and this was as a result of the unavailability of resources as well as increased load on both teachers and learners. This triggered resistance to the implementation of the CA. Dube and Jita, (2018) contend teachers had challenges in syllabus interpretation and lacked resources such as instructional media. Hence were not equipped to execute the new curriculum aspect.

Teachers could not perform their assigned tasks because they were not knowledgeable about the curriculum tasks or projects. Literature shows that teachers should be clear about the materials such as knowledge content, teaching methodology of the curriculum as well as experience for them to effectively implement a curriculum change (Kazu \& Demiralp, 2016). To support this view, Ornstein and Hunkins (2004) allude that teachers should have adequate knowledge about the CA first and fore most because teaching is influence by teachers. Thus teachers should not grope in the darkness but should provide the light to learners. Bernnet (2007) adds that lack of professional development for teachers working with curriculum inhibited the implementation. Thus the fact that teachers were not prepared to implement the curriculum.

\section{Conclusion and Recommendations}

This part gives the conclusions and recommendations of the study, based on the findings.

\section{Conclusions}

Based on the findings, the study concludes that important stakeholders such as parents, teachers and learners did not support the implementation of the continuous assessment aspect in school curriculum because they felt that they were not part of the newly introduced aspect. It is also concluded that teachers could not competently supervise the project from ZIMSEC due to lack of knowledge. Teaching tasks were too many because every learning area had a task implying an extra work load for both the teachers and learners and since teachers were not prepared, the implementation failed. Therefore, lack of preparedness was the major reason that hindered the implementation of the newly introduced curriculum aspect, the implementation of the Continuous Assessment.

\section{Recommendations}

Based on the above conclusions, the researchers recommend that important stakeholders in education such as parents, teachers and learners should be involved in the inception of new aspects 
in the curriculum. Staff development programs for teachers are encouraged to make sure that teachers are confident to implement new changes in the curriculum before the changes are implemented. Finally, teaching manuals, stationeries and other facilities should be provided in time and in adequate quantities so that no school will lag behind due their different circumstances when the new changes are introduced.

\section{Reference}

Abejehu, S.B. (2016). The Practice of Continuous Assessment in Primary Schools: The Case of Chagni, Ethiopia. Journal of Education and Practice 7(31), 2016.

Agonafer, S. \& Tadese, W. (2015). The Challenges of Implementing CA in Physical Education in some selected Secondary Schools in Metekel Zone of Benshangul Gumuz Regional State, Ethiopia, Abhinav National Monthly Refereed Journal of Research in Arts and Education 7, 16-21.

Ali, A.A. and Ajibola A.L. 92015).issues and Prospects of Effective Implementation of New Secondary School Curriculum in Nigeria, Journal of Educational Practice, 6, (34) 2939.

Bedada, T.A. (2012).The State of Continuous Assessment Practices in Secondary Schools of Oromia Special Zone: Challenges and Prospects. Addis Ababa University. Ethiopia .

Berhe \& Embiza (2015). Problems and Prospects of Implementing Continuous Assessment at Adigrat University. Journal of Education and Practice 6, (4).

Chaurura, L.B. (2017). The Effect of Continuous Assessment to Students Performance in Summative Assessment: Case of Economics Advanced Level Students at Kazangarare High School in Hurungwe Rural. Masters Dissertation, Bindura University of Science Education.

Cooper, T. (2017). Curriculum Renewal: Barriers to Successful Curriculum Change andSuggestions for Improvement, Journal of Education and Training Studies Vol. 5, No. 11; November 2017ISSN 2324-805X E-ISSN 2324-8068. Published by Redfame Publishing URL: http://jets.redfame.com 115.
Creswell, J.W. \& Creswell, J.D. (2018). Research Design, ( $5^{\text {th }}$ Edition) London. Sage Edge Publishers.

Curriculum Framework for Primary and Secondary Education (2015-2022). Ministry of Primary and Secondary Education, Harare.

Der Berg, S. V. \& Shepherd, D. (2015) Signalling performance: Continuous assessment and matriculation examination marks in South African schools. Stellenbosch Economic Working Papers: 28/10 Stellenbosch University.

Dube, B. and Jita, T. (2018). Rethinking healthy school relations for curriculum change in Zimbabwe: A relational leadership approach. Issues in Educational Research, 28(4), 901-917.

Elliot, S.N.Katochwill,T.R.Littlefield Cook, J and Travers, J.(2000). Educational Psychology: Effective Teaching, Effective learning, $\left(3^{\mathrm{RD}}\right.$ Edition). Boston.M.A: McGraw-Hill College.

Ferreira, C and Schulze, S. (2014). Teachers experience of the implementation of values in Education in Schools. Mind the Gap. South African Journal of Education 34(1).

The Herald (7, July 2017). Continuous Assessment, p.1, Harare, Zimpapers.

Kapambwe, W.M. (2010). The implementation of school based continuous assessment (CA) in Zambia Educational Research and Reviews Vol. 5(3), 99-107.

Kazu, H. and Demiralp, D. (2016). Faculty Members' Views on the Effectiveness of Teacher Training Competences. Eurasian Journal of Educational Research Issue 63 205-224.

Kidane, A. (2013). The Challenges of Implementing Continuous Assessment in Physical education Classes in some selected High Schools, Addis Ababa University, Ethiopia.

Makuvaza, N. (2018). Celebrating the Ministry of Primary and Secondary Education Curriculum Framework for Zimbabwe (20152022). Zimbabwe Journal for Educational Research 1(March 2018), 46-67

Maravanyika, O.E. (2018). Possibilities for Enhancing Efficacy in the current Curriculum Review Exercise through Curriculum Analysis. Zimbabwe Journal of Educational Research 1, 68-75. 
Ministry of Primary and Secondary Education (2016). Curriculum Framework for Primary and Secondary Education, 2015-2022, Harare. MoPSE.

Nherera, C.M. (2018). Rethinking Technical Education and Vocational Education and Training in the Context of the New Curriculum Frame work for Primary and Secondary Schools (2015-2022). Zimbabwe Journal of Educational Research 1 (March 2018), 122-139.

Nkala, S. (2017). Dadaya case against Dokora Stalls. Neswday, 14 February.

Nziramasanga, C.T. (2018). Curriculum Review Process in the Context of ZIMASSET: Possible Linkages with the CIET Provisions. Idle hands make one poor, diligent hand bring riches (Proverbs 10:4). Zimbabwe Journal of Educational Research 1, 36-45

Nziramasanga, C. T. (1999). Report on the Presidential Commission of Inquiry into
Education and Training. (August 1999). Harare: Government Printers.

OECD (2019). Development Co-operation Report. http://doi.org/10.1787/20747721. Accessed on24 Novembe 2020

Ornstein, A. C. and Hunkins, F. P. (2004) Curriculum: Foundations, Principles, and Issues, 4th Edition, Toronto, Pearsson.

Ridder, H. (2017). The theory contribution of case study research designs. Business Research 10,281-305

Sanders, M. N. K. , Lewis, P and Thornhill, A (2019). Reseacch Methods for Business Students. London, Pearson.

The Sunday News, (3 June 2018). Ministry to Reintroduce Continuous Assessment in Schools, p.1, Harare, Zimpapers.

Zindi, F. (2018).Zimbabwe Teachers' Concerns Regarding the Implementation of the New Curriculum. Zimbabwe Journal of Educational Research 1 (March 2018), 2535. 